\title{
NUMERICAL ANALYSIS OF HEAT SINKS FOR LED LIGHTING MODULES
}

\author{
Royston Marlon Mendonca ${ }^{1}$, Sai Sharan Yalamarty ${ }^{2}$, Chandrakant R Kini $^{3}$ \\ ${ }^{I}$ Department of Mechanical and Manufacturing Engineering, Manipal Institute of Technology, India \\ ${ }^{2}$ Department of Mechanical and Manufacturing Engineering, Manipal Institute of Technology, India \\ ${ }^{3}$ Department of Mechanical and Manufacturing Engineering, Manipal Institute of Technology, India
}

\begin{abstract}
LEDs provide efficient lighting solutions. Their main advantages are efficiency, reliability and durability. Although LEDs operate cooler than conventional incandescent bulbs, it is necessary to achieve maximum heat transfer in order to maintain or improve their efficiency and lifespan. Heat sinks in LED modules provide a path for heat to flow from the source to the outside ambience. Heat sinks with different fin geometries are analyzed to determine its influence on thermal performance and airflow around the fins. By comparing different fin geometries, the thermal performance and airflow are compared and analyzed. It was found that the airfoil fins with reverse orientation offers the minimum resistance. Airfoil is the most commonly used shape in applications where aerodynamics is of major importance.
\end{abstract}

Keywords: Light-emitting diodes, Thermal performance, Cooling, Numerical Analysis

$* * *$

\section{INTRODUCTION}

LEDs have replaced the use of traditional lamps as they provide numerous advantages over them. They are free from mercury, hence they are environmental friendly. LEDs are capable of converting electricity directly to light energy, causing less heat to be generated and minimal waste of energy. They also consume about one-third the power and have a lifespan that is about tenfold. Such advantages make LEDs an attractive option for several applications.

Researchers have reported many cooling techniques, including liquid cooling techniques, for high power LED lighting modules. Wang et al. have developed vapor chamber based plate for 30W high power LEDs [11]. Luo and Liu have proposed a micro jet array cooling system for a 220W LED lamp [10]. Kim and Bar-Cohen et al. have developed a direct sub- mount cooling technique using FC72 as a working fluid [5]. Lin et al. have investigated thermal characteristics of aluminum plate oscillating heat pipes [8]. Liu et al. have numerically investigated a micro jet cooling system with three different micro jet structures [9]. Xiang et al. have reported phase change heat sinks fabricated for LED packages cooling [12]. Research for the development of heat sinks with extended surfaces is much less when compared to research work on liquid cooling of heat sinks. Elshafi proposed hollow /perforated pin fin heat sinks, when compared to solid pin fin heat sinks, showed better results in terms of cooling performance [3]. A preliminary study with respect to the thermal behavior of the hybrid fin heat sinks were analyzed [6], the hybrid fin heat sinks would be lighter and improve cooling performance compared to classical heat sinks such as pin fin heat sinks.

\section{FIN GEOMETRIES}

In this section, the physical structure of the fins is discussed. Five basic geometries are introduced to discuss the effect on thermal performance and airflow. The cross-sectional area is kept constant while modifying the shape. A total of 23 fins were placed on a base of dimensions $75 \mathrm{~mm} \times 75 \mathrm{~mm} \times 5 \mathrm{~mm}$. Each fin has a height of $50 \mathrm{~mm}$. Fin spacing of $15 \mathrm{~mm}$ was chosen for all geometries as it was found to produce the best results [6].The fin geometries were modeled using CATIA [2]. The material used for the heat sink is aluminum 2024 [7].

\section{Pin Fin (Cylinder)}

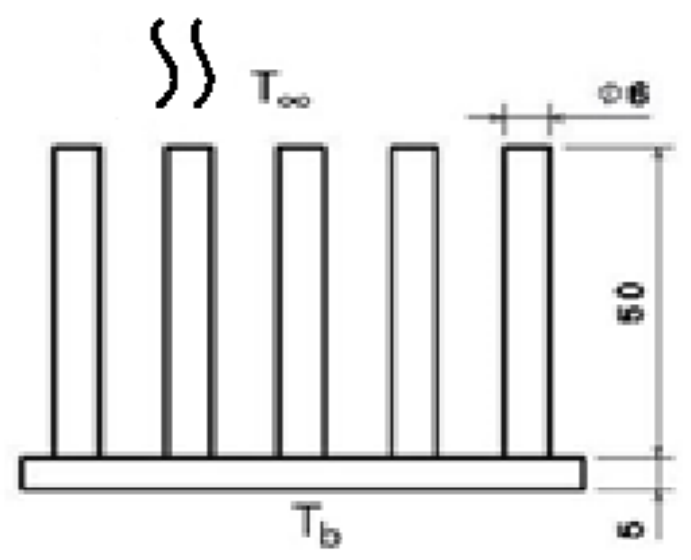

(A) 


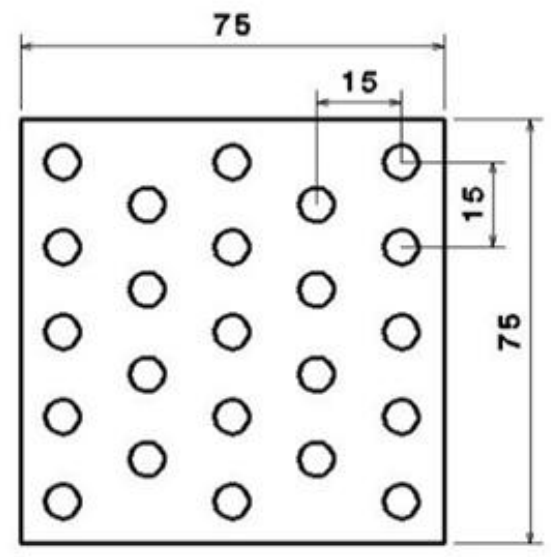

(B)

Fig-1: (A) 3D representation of the pin fin model, (B) 2D representation along with dimensions

Figure 1(A) shows the structure of the pin fin model and Figure 1(B) shows the dimensions of the pin fin model. Fig 2(A) and 2(B) represent the isometric view and top view respectively for a triangular cross-section. The edges of the fins with a triangle cross-section are filleted in order to provide smooth airflow around the fins. Fig 3(A) and 3(B) represent the isometric view and top view respectively for an elliptical cross-section. Fig 4(A) and 4(B) represent the isometric view and top view respectively for an airfoil fin. Fig 5(A) and 5(B) represent the isometric view and top view respectively for an airfoil fin where the trailing edge faces the incoming airflow.

\section{Triangle}

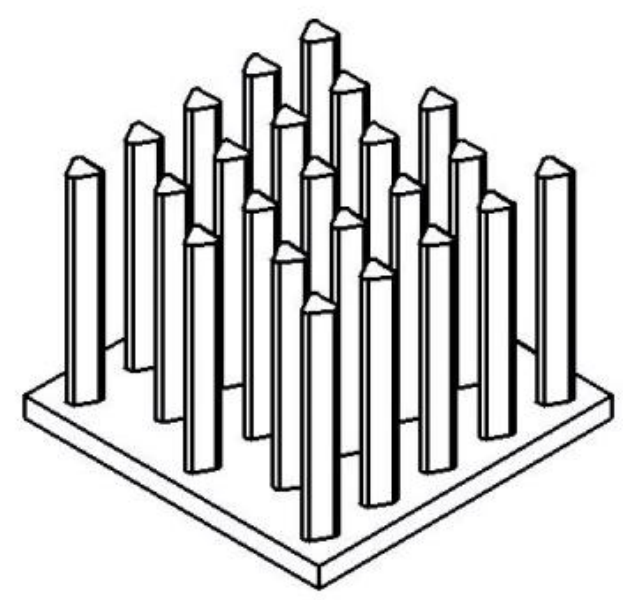

(A)

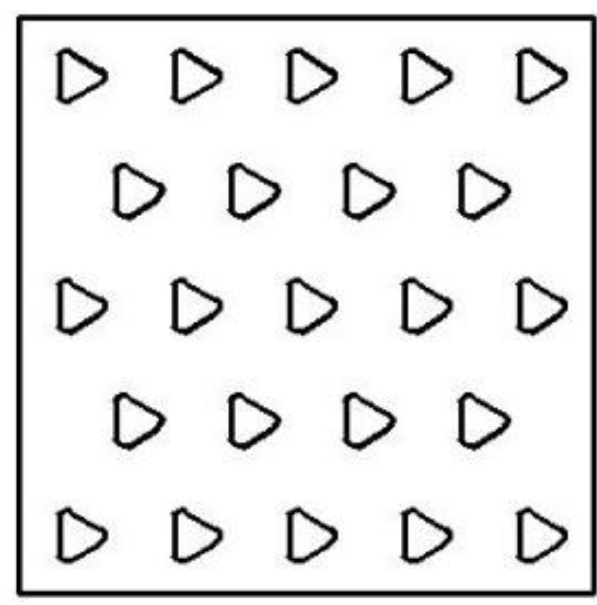

(B)

Fig-2: (A) 3Drepresentation of the fins with triangle crosssection, (B) 2D representation

\section{Ellipse}

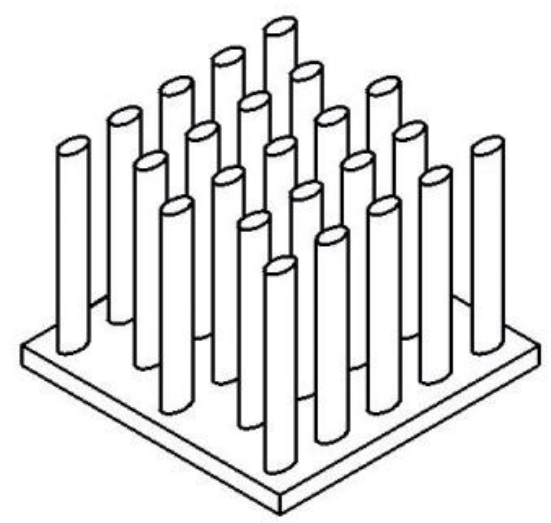

(A)

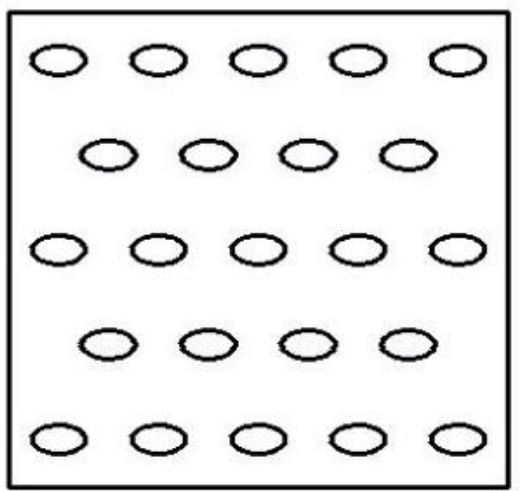

(B)

Fig-3: (A) 3Drepresentation of the fins with elliptical crosssection, (B) 2D representation 


\section{Airfoil}

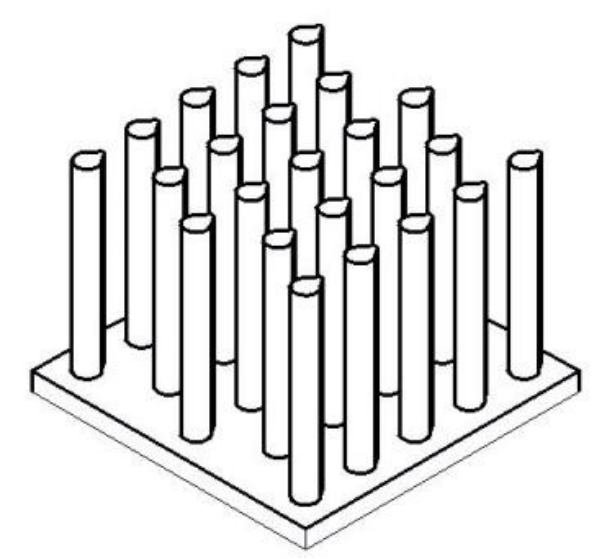

(A)

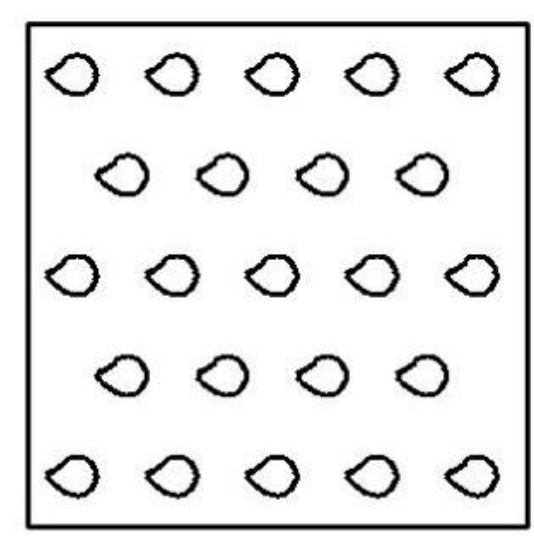

(B)

Fig-4: (A) 3Drepresentation of the airfoil fins, (B) 2D representation

\section{Airfoil (Reverse Orientation)}

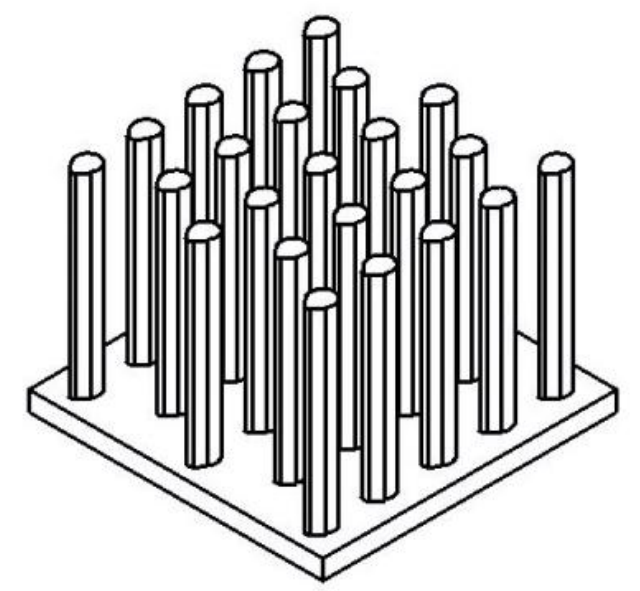

(A)

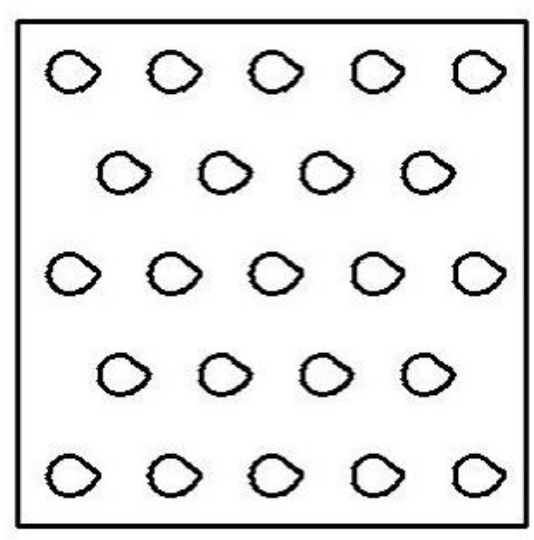

(B)

Fig-5: (A) 3D representation of the airfoil fins with reverse orientation, (B) 2D representation

\section{COMPUTATIONAL STUDY}

\subsection{Computational Model}

Thermal performance of the hybrid model was analyzed and compared to the pin fin model using ANSYS Fluent and the mesh was generated on ANSYS Workbench [1]. Figure 6 shows grid dependence test based on mesh size to check the quality of mesh for solution accuracy. It is clear from the figure that temperature values do not deviate more than $1 \%$ between two mesh sizes of $5.7009 \mathrm{e}-005 \mathrm{~m}$ and $4.6352 \mathrm{e}-$ $005 \mathrm{~m}$. Hence mesh size of $5.7009 \mathrm{e}-005 \mathrm{~m}$ is taken as the appropriate size due to reduced computational time. The mesh consists of $3.61 \times 10^{5}$ nodes and $2.11 \times 10^{6}$ elements. The following equations govern the CFD analysis [4]:

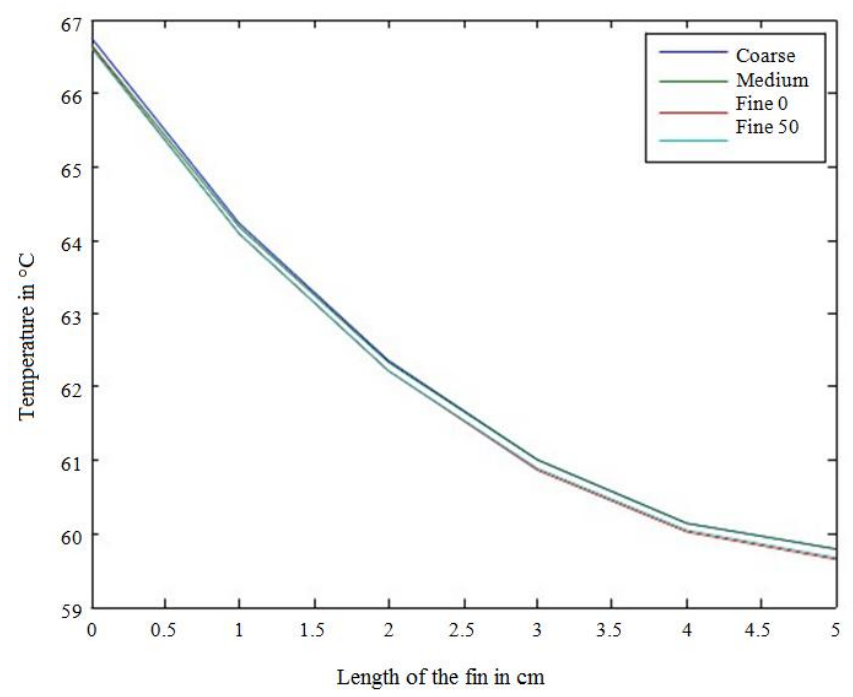

Fig-6: Results of Grid Dependence test

Conservation of mass:

$\frac{\partial u_{k}}{\partial x_{k}}=0$ 
Conservation of momentum:

$$
\frac{\partial}{\partial x_{k}}\left(\rho u_{j} u_{i}\right)=\frac{\partial}{\partial x_{j}}\left[-p \delta_{i j}+\mu\left(\frac{\partial u_{i}}{\partial x_{j}}+\frac{\partial u_{i}}{\partial x_{i}}\right)\right]+\rho g_{i}
$$

Conservation of energy:

$$
\frac{\partial}{\partial x_{j}}\left[\rho u_{j}\left(h+\frac{1}{2} u_{i}^{2}\right)\right]-\frac{\partial}{\partial x_{j}}\left(k \frac{\partial T}{\partial x_{j}}\right)=0
$$

$u_{k} \rightarrow$ Velocity, $x_{k} \rightarrow$ Cartesian coordinate direction, $\rho \rightarrow$ Density, $p \rightarrow$ Pressure $h \rightarrow$ Enthalpy, $k \rightarrow$ Thermal conductivity and $\delta_{i j}=1$

\subsection{Boundary Conditions}

A uniform heat flux of $30 \mathrm{~W}$ [3] is applied to the bottom surface of the base and a velocity of $1 \mathrm{~m} / \mathrm{s}$ [3] is given as the inlet boundary condition and atmospheric pressure is given as outlet boundary condition. Laminar and steady state conditions are assumed, and the ambient temperature chosen is $25^{\circ} \mathrm{C}[3]$.

\section{THERMAL PERFORMANCE}

In this section, the thermal performance and airflow for different fingeometries are analyzed and discussed. Table 1 shows the resistance offered by different fin geometries along with their efficiencies. Figure 7 to Figure 11 show the temperature plots and airflow patterns around the fins of different geometries. Although the efficiency of pin fin is higher than that of reverse airfoil, reverse airfoil type fin gives a better performance due toincreased surface area and better air flow when the fins are in an array.

Table -1: Resistance, Total Surface Area and Relative Efficiency for different fin geometries

\begin{tabular}{|l|l|l|l|l|}
\hline $\begin{array}{l}\text { SI } \\
\text { No. }\end{array}$ & $\begin{array}{l}\text { Fin } \\
\text { Geometries }\end{array}$ & $\begin{array}{l}\text { Resistance } \\
\text { in K/W }\end{array}$ & $\begin{array}{l}\text { Total } \\
\text { Surface } \\
\text { Area ( } \\
\left.\times \quad \mathbf{1 0}^{-2}\right) \\
\mathbf{m}^{2}\end{array}$ & $\begin{array}{l}\text { Fin } \\
\text { Efficiency } \\
\left(\mathrm{\eta}_{f}\right)\end{array}$ \\
\hline 1 & $\begin{array}{l}\text { Circular } \\
\text { (Pin Fin) }\end{array}$ & 1.406 & 2.87401 & $93.47 \%$ \\
\hline 2 & Triangle & 1.426 & 3.02565 & $92.49 \%$ \\
\hline 3 & Ellipse & 1.453 & 3.01160 & $92.99 \%$ \\
\hline 4 & Airfoil & 1.403 & 3.02527 & $93.44 \%$ \\
\hline 5 & $\begin{array}{l}\text { Reverse } \\
\text { Airfoil }\end{array}$ & 1.373 & 3.02527 & $93.44 \%$ \\
\hline
\end{tabular}

The following equation is used to calculate resistance:

$$
R=\frac{\mathrm{T}_{\mathrm{B}}-\mathrm{T}_{\mathrm{BO}}}{\mathrm{Q}}
$$

$\mathrm{T}_{\infty} \rightarrow$ Ambient Temperature in ${ }^{\circ} \mathrm{C}$

$\mathrm{T}_{\mathrm{B}} \rightarrow$ Highest Temperature of base of the module in ${ }^{\circ} \mathrm{C}$

$\mathrm{Q} \rightarrow$ Heat supplied in 'Watts'

$\mathrm{R} \rightarrow$ Resistance in ' $\mathrm{K} / \mathrm{W}$ '
The following equation is used to calculate fin efficiency:

$$
\eta_{f}=\frac{\mathrm{Q}_{\mathrm{f}}}{\mathrm{hA \theta}}
$$

$\mathrm{Q}_{\mathrm{f}} \rightarrow$ Heat transfer from fin in 'Watts'

$\mathrm{h} \rightarrow$ Heat transfer coefficient in $\mathrm{W} / \mathrm{m}^{2} \mathrm{~K}$

A $\rightarrow$ Surface Area of fins in $\mathrm{m}^{2}$

$\theta \rightarrow$ Temperature difference between the fin base and the ambient in ${ }^{\circ} \mathrm{C}$

It was found that the airfoil fins with reverse orientation offered a resistance of $1.373 \mathrm{~K} / \mathrm{W}$, which was the least among all the shapes tested. With the trailing edge facing the incoming airflow, fins arranged in the same row created a converging section for airflow. This increases air velocity, thus improving cooling. Although a triangular cross-section provided the same converging effect as that of an airfoil, the deviation of airflow around the fins was slightly higher and air velocity was greater next to boundary walls and lower through the fins, proving to be less effective comparatively. Fins with an elliptical cross-section proved to be the least effective. Unlike the other geometries, the amount of turbulence is lower through the fins resulting in comparatively hotter fins. 


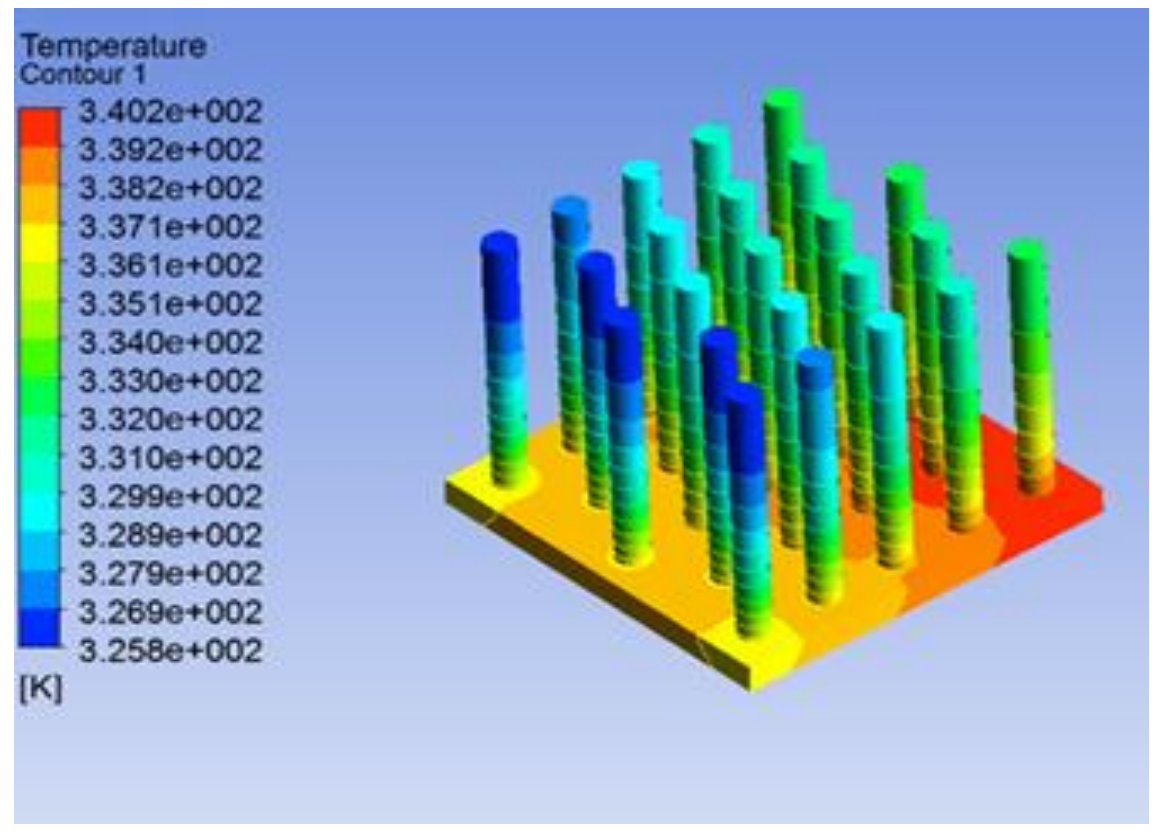

(A)

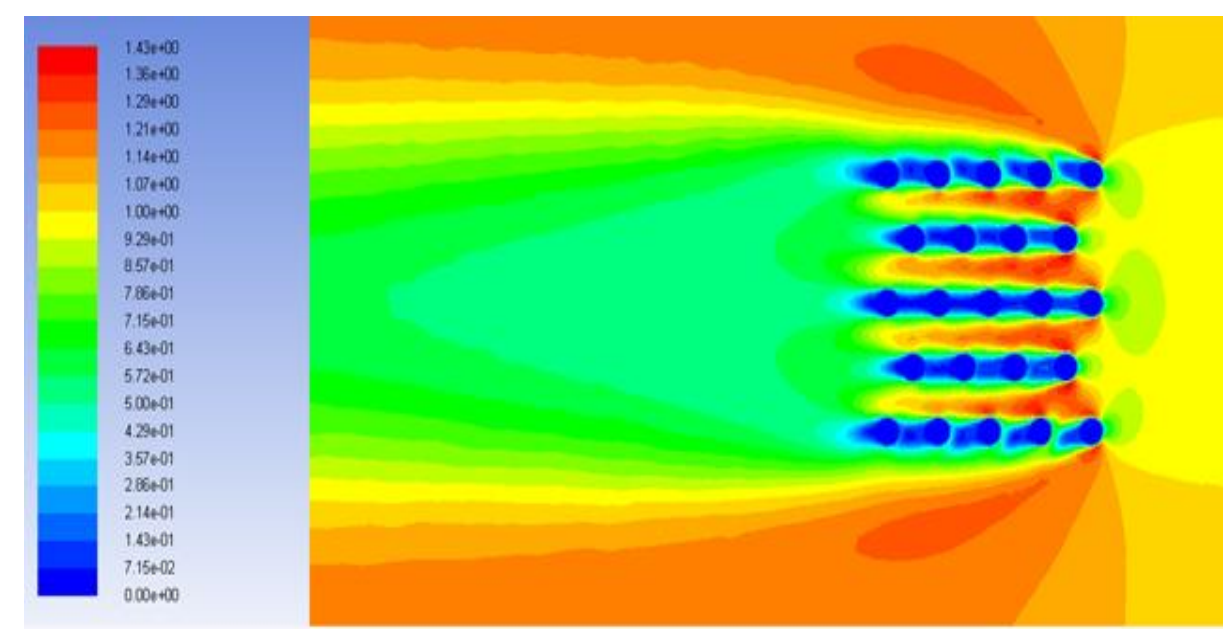

(B)

Fig-7: (A) Temperature plot of pin fins (B) Airflow around pin fins

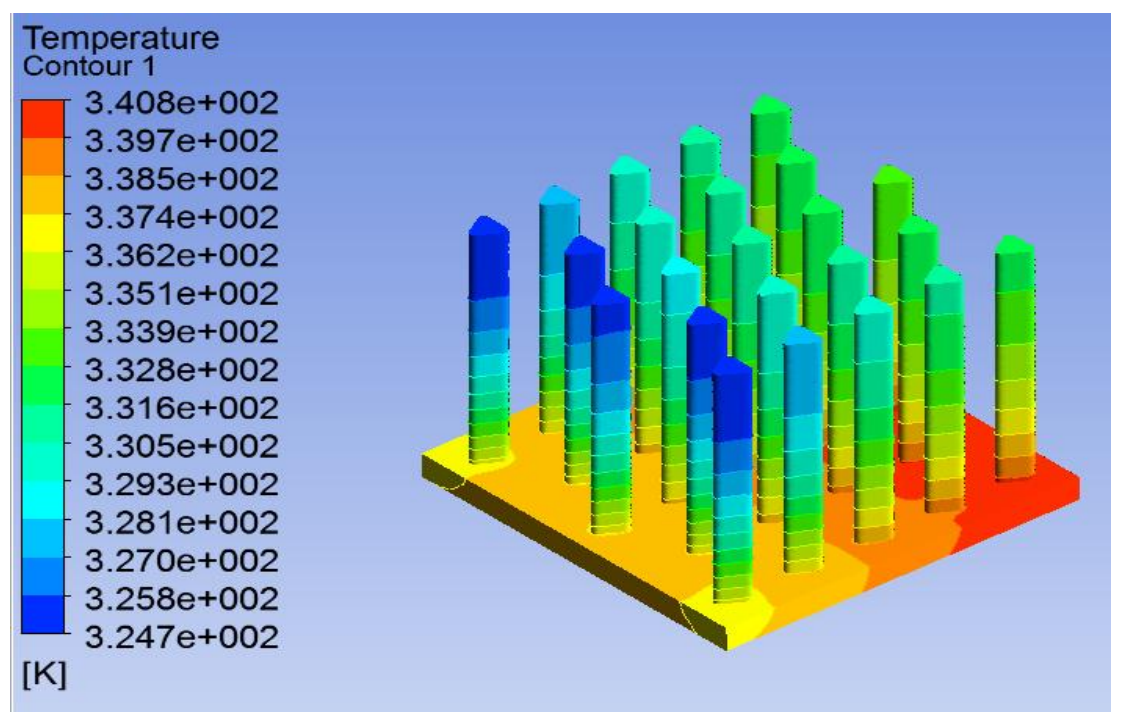

(A) 


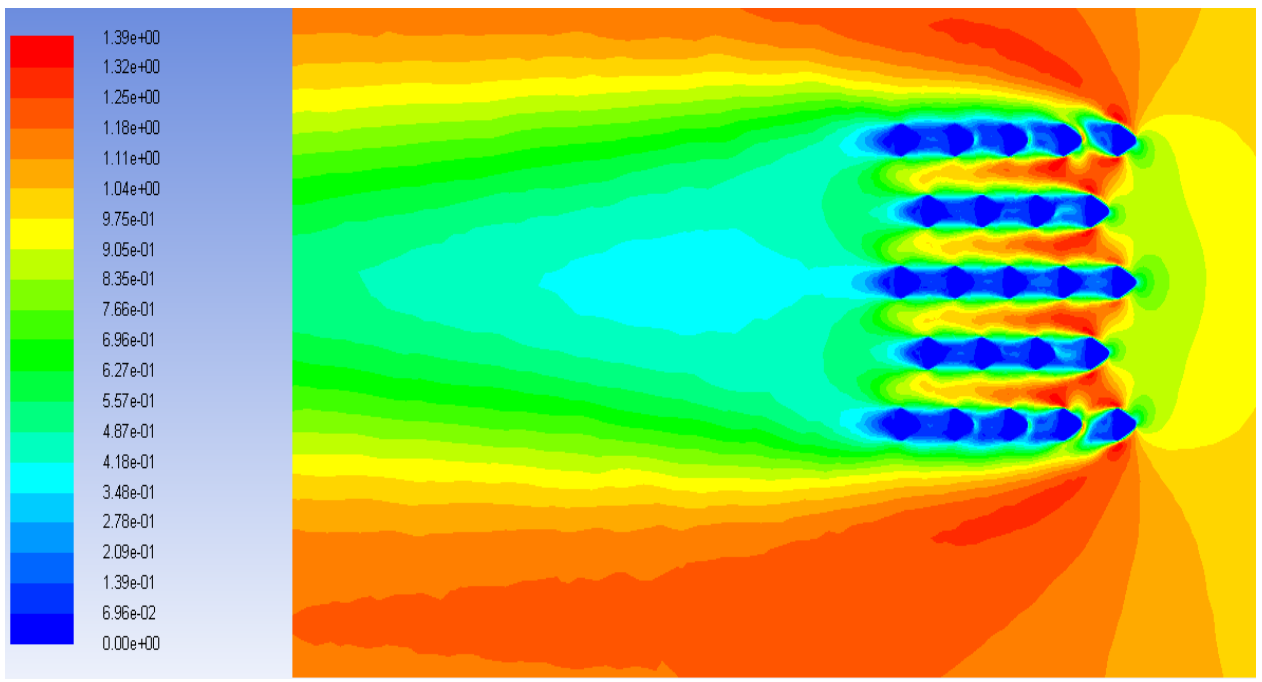

(B)

Fig-8: (A) Temperature plot of triangular fins (B) Airflow around triangular fins

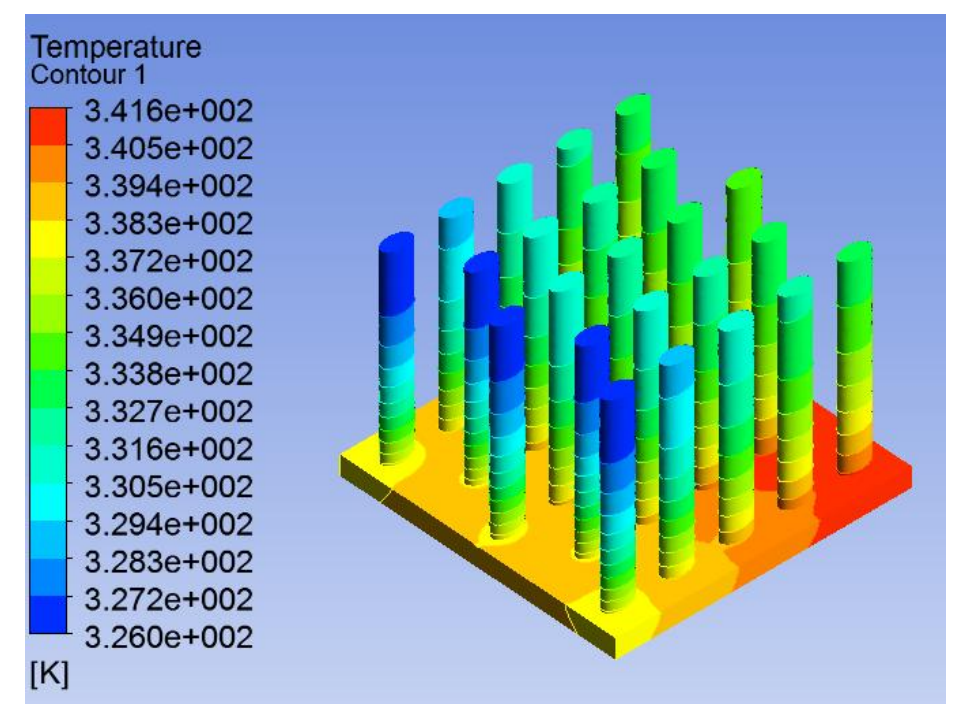

(A)

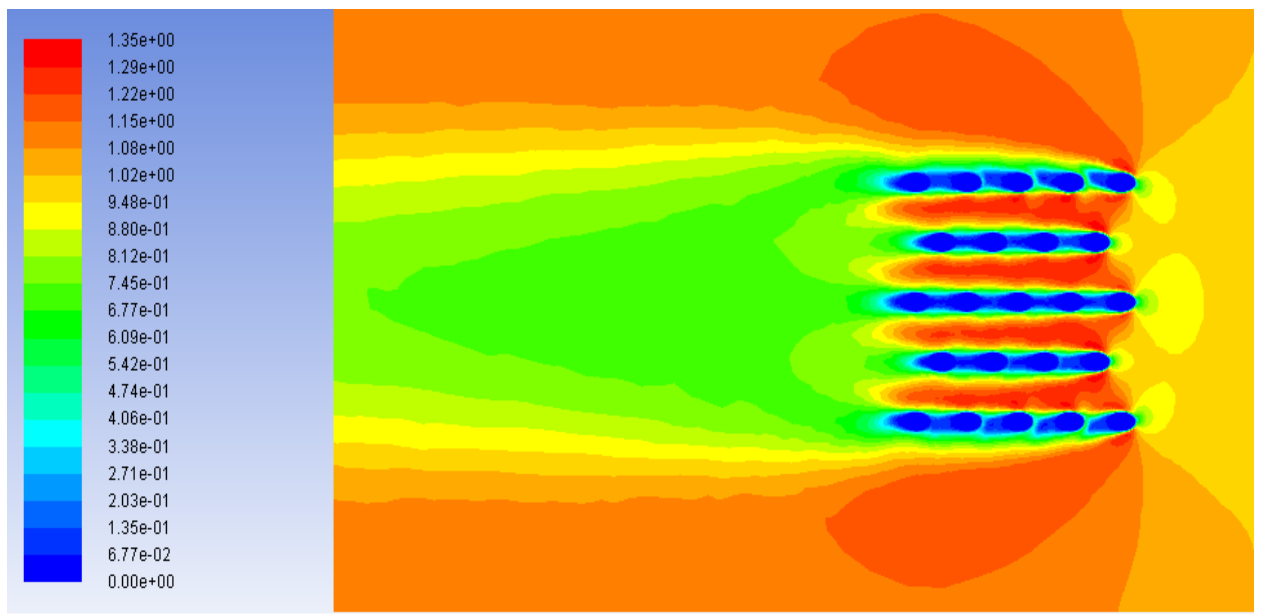

(B)

Fig-9: (A) Temperature plot of elliptical fins (B) Airflow around elliptical fins 


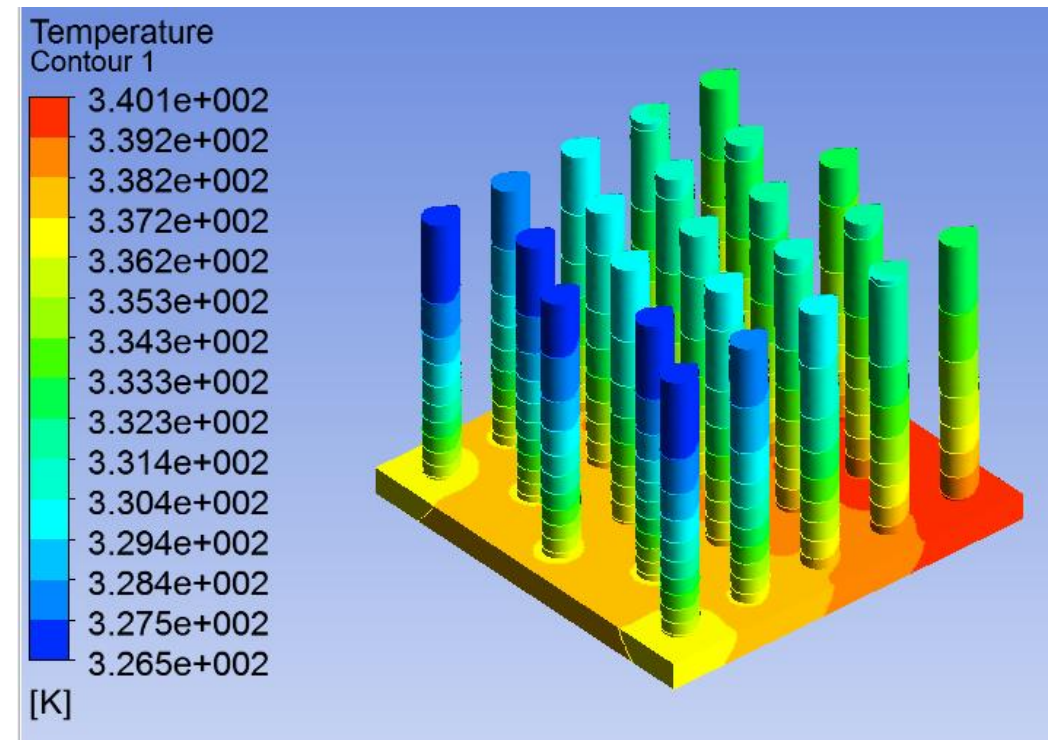

(A)

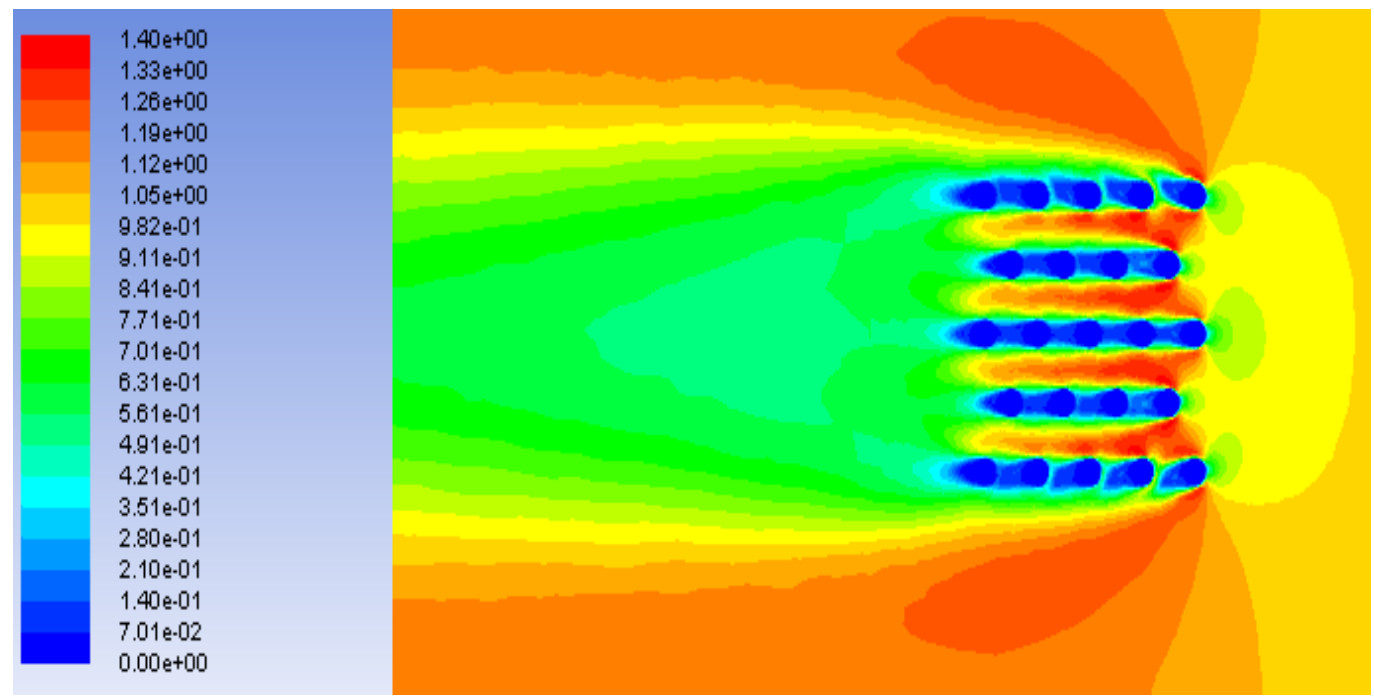

(B)

Fig-10: (A) Temperature plot of airfoil fins (B) Airflow around airfoil fins

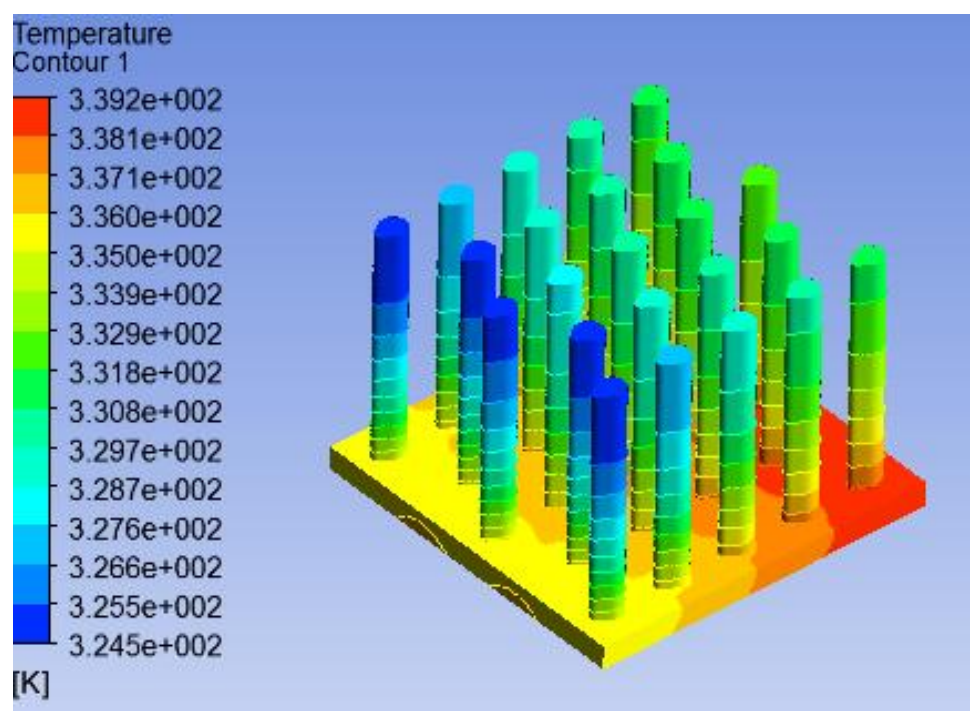

(A) 


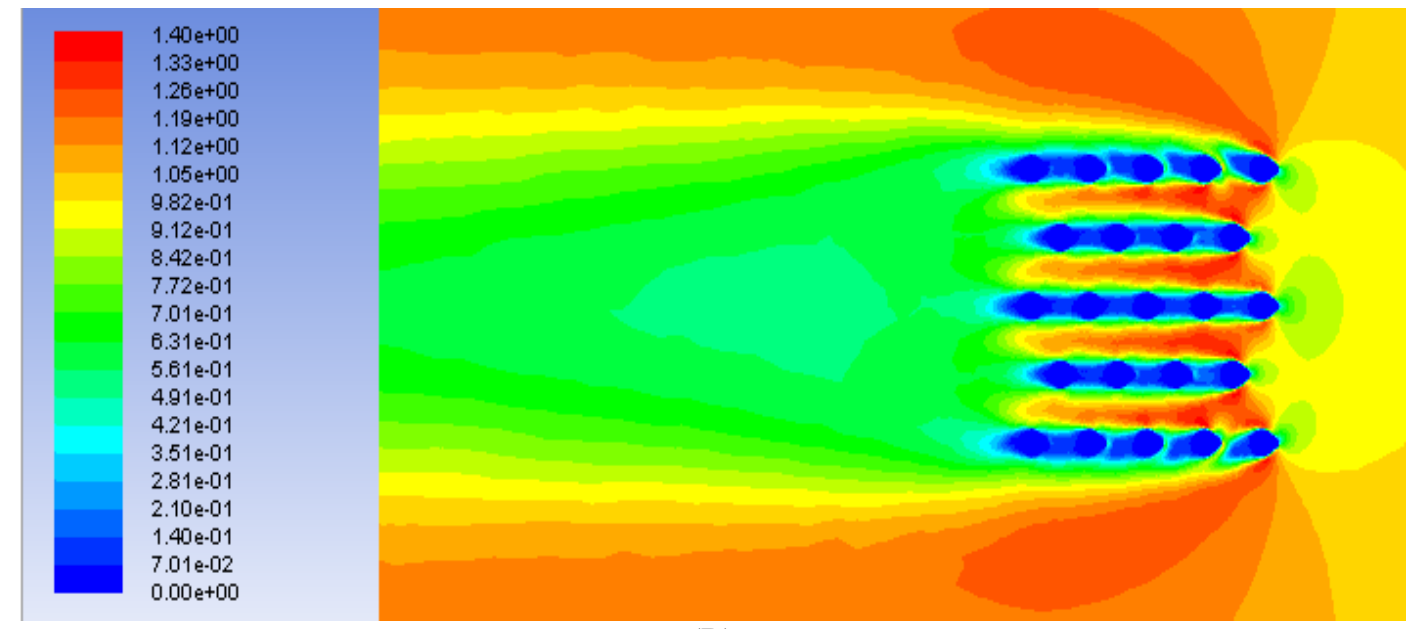

(B)

Fig-11: (A) Temperature plot of airfoil fins with reverse orientation (B) Airflow around airfoil fins with reverse orientation

\section{CONCLUSION}

By comparing different fin geometries, the thermal performance and airflow are compared and reported. It was found that the airfoil fins with reverse orientation offers the minimum resistance. Efficiency for the pin fin was found to be the highest. Airfoil is the most commonly used shape in applications where aerodynamics is of major importance. The several configurations of an airfoil introduces the possibility of further research into controlling airflow and thermal performance, thus resulting in cooler operation of LEDs and a higher lifespan.

\section{REFERENCES}

[1]. ANSYS Workbench, ANSYS Workbench User's Guide, Release 15.0, ANSYS Inc., Canonsburg, USA;2013

[2]. CATIA V5R19, Dassault Systems, 1994-2011.

[3]. Elshafei, E. A. M., 2010, "Natural Convection Heat Transfer from a Heat Sink with Hollow/Perforated Circular Pin Fins," Energy, 35(7), pp. 2870-2877.

[4]. Hoffmann, K. A. and Chiang, S. T., 1998, Computational Fluid Dynamics, Vol. I, 3rd ed., Engineering Education System, Wichita, KS.

[5]. Kim, D.-W., Rahim, E., Bar-Cohen, A., and Han, B., 2010, "Direct Sub mount Cooling of High-Power LEDs," IEEE Trans. Compon. Packag. Technol., 33(4), pp. 698712.

[6]. Kim, H., Kim, K. J., and Lee, Y., 2012, “Thermal Performance of Smart Heat Sinks for Cooling High Power LED Modules," 13th IEEE Intersociety Conference on Thermal and Thermomechanical Phenomena in Electronic Systems (ITherm), San Diego, CA, May 30-June 1, pp. 962-967.

[7]. Kyoung Joon Kim, "Performance of Hybrid Fin Heat Sinks for Thermal Control of Light Emitting Diode Lighting Modules", Journal of Electronic Packaging, MARCH 2014, Vol. 136, pp. 011002-1 - 011002-6

[8]. Lin, Z., Wang, S., Huo, J., Hu, Y., Chen, J., Zhang, W., and Lee, E., 2011, "Heat Transfer Characteristics and LED
Heat Sink Application of Aluminum Plate Oscillating Heat Pipes," Appl. Therm. Eng., 31(14), pp. 2221-2229.

[9]. Liu, S., Yang, J., Gan, Z., and Luo, X., 2008, "Structural Optimization of Micro jet Based Cooling System for High Power LEDs,” Int. J. Therm. Sci., 47, pp. 1086-1095.

[10]. Luo, X., and Liu, S., 2007, “A Micro jet Array Cooling System for Thermal Management of High-Brightness LEDs," IEEE Trans. Adv. Package., 30(3), pp. 475-484.

[11]. Wang, J.-C., Wang, R.-T., Chang, T.-L., and Hwang, D.-S., 2010, "Development of 30 Watt High Power LEDs Vapor Chamber Based Plate," Int. J. Heat Mass Transfer, 53(19), pp. 3990-4001.

[12]. Xiang, J.-H., Zhang, C.-L., Jiang, F., Liu, X.-C., and Tang, Y., 2011, "Fabrication and Testing of Phase Change Heat Sink for High Power LED," Trans. Nonferrous Met. Soc. China 21, pp. 2066-2071.

\section{BIOGRAPHIES}

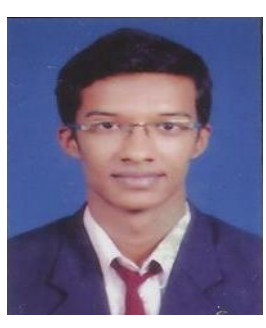

Royston Mendonca is the First Author studying in the Final year of Bachelor of Technology in Mechanical Engineering, Manipal Institute of Technology, Manipal University, India. His area of research includes Heat Transfer, Fluid mechanics and IC Engines.

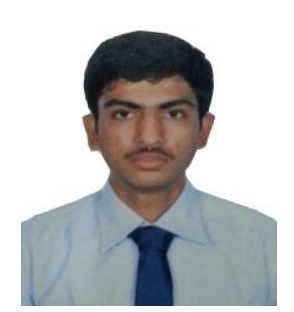

Sai Sharan is the Second Author studying in the Final year of Bachelor of Technology in Mechanical Engineering, Manipal Institute of Technology, Manipal University, India. His area of research includes Heat Transfer and Fluid Mechanics. 


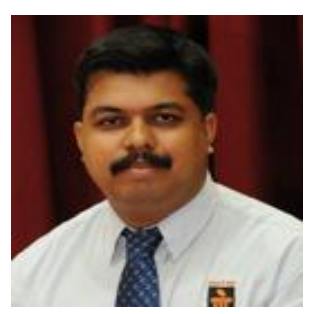

Chandrakant $\mathrm{R}$ Kini is the Corresponding Author working as Assistant Professor (Selection Grade) in the Department of Mechanical and Manufacturing Engineering, Manipal Institute of Technology, Manipal University, India. $\mathrm{He}$ has B.E in Mechanical Engineering and $M$.

Tech in Thermal Engineering from NITK, Surathkal. Presently he is doing $\mathrm{PhD}$. His area of research includes CFD analysis of Gas Turbine Blade cooling, heat transfer, materials and metallurgy. 